\title{
Effects of compound or element preexposure on compound flavor aversion conditioning
}

\author{
PETER C. HOLLAND and DESWELL T. FORBES \\ University of Pittsburgh, Pittsburgh, Pennsylvania 15260
}

\begin{abstract}
Two experiments with rat subjects examined conditioning of an aversion to a compound flavor stimulus after preexposing the compound, its constituent elements, or no explicit flavor stimulus. Experiment 1 used a short-term procedure in which preexposure and conditioning treatments occurred on the same day; Experiment 2 used a long-term procedure in which more extensive preexposure was administered several days before conditioning. In both experiments, preexposure of the elements slowed conditioning to the compound more than did preexposure of the compound itself. These effects were apparently not mediated by changes in pseudoconditioned or neophobic responses. The results were related to Lubow's conditioned attention theory of stimulus preexposure effects.
\end{abstract}

Conditioning is retarded if nonreinforced presentations of the conditioned stimulus (CS) occur prior to the conditioning experience. This outcome has been observed in a wide variety of preparations and has been variously termed latent inhibition (Lubow, 1973), learned irrelevance (Mackintosh, 1973), or learned safety (Kalat \& Rozin, 1973). The experiments reported here examined the effects of preexposing a flavor compound CS or its individual elements on flavor aversion conditioning of that compound flavor CS.

Rescorla and Wagner (1972) noted that greater conditioned responding to a compound CS can be generated by conditioning its constituent elements individually than by conditioning the compound itself. If, as a number of investigators have suggested (e.g., Kalat \& Rozin, 1973; Lubow, Schnur, \& Rifkin, 1976), stimulus preexposure effects involve associative learning of some sort, the conditionability of a compound CS might be more decremented by preexposing its constituent elements than by preexposing the compound itself.

The experiments reported here used a flavor-aversion conditioning situation for a variety of reasons. First, that situation allows convenient observation of stimulus preexposure effects: even a single preexposure trial often results in large deficits in subsequent conditioning (e.g., Domjan \& Bowman, 1974; Kalat \& Rozin, 1973). Second, preexposure effects have been accorded greater theoretical importance in that preparation than in other preparations; such effects have encouraged the postulation of new learning processes such as learned safety (Kalat \& Rozin, 1973) and have been implicated in other basic conditioning phenomena such as the CS-US delay gradient (e.g., Domjan

This research was supported in part by Grant BNS 7903853 from the National Science Foundation.
\& Bowman, 1974) in flavor aversion conditioning. Third, few investigations of compound conditioning using the flavor aversion preparation have been reported (e.g., Malone \& Cox, 1971; Rescorla \& Cunningham, 1978); we hope to encourage the use of that preparation for the study of compound conditioning by describing other features of compound flavor aversion conditioning.

Conditioning to a compound flavor stimulus paired with lithium chloride ( $\mathrm{LiCl}$ )-induced illness was observed after preexposure of that compound, its element flavors, or no explicit flavor. In Experiment 1, preexposure and conditioning treatments occurred during the same day; in Experiment 2, preexposure was extended over several days and was less proximal to the conditioning phase.

\section{EXPERIMENT 1}

\section{Method}

Subjects and Apparatus. The subjects were 36 experimentally naive male Sprague-Dawley rats about 150 days old at the beginning of the experiment. They were housed in individual $20 \times 20$ $\times 25 \mathrm{~cm}$ cages in a colony room that was illuminated from $6: 30 \mathrm{a} . \mathrm{m}$. to $8: 30$ p.m. Each cage was fitted with a wire rack which permitted a calibrated drinking tube $(100 \mathrm{ml}$, Wahman No. LC274) to be presented. The stainless steel nozzle of this tube extended $3 \mathrm{~cm}$ inside the front wall of each cage, $10 \mathrm{~cm}$ from one side and $3 \mathrm{~cm}$ from the floor. Purina Lab Chow was available ad lib in these cages throughout the experiment.

Stimuli. The flavored solutions used as stimuli in this experiment were $.2 \mathrm{M} \mathrm{NaCl}(\mathrm{Na}), .1 \mathrm{M}$ sucrose (S), and a compound $(\mathrm{NaS})$ of these two solutions $(.1 \mathrm{M}$ sucrose $+.2 \mathrm{M} \mathrm{NaCl})$, mixed so as to maintain the molarities of the individual solutions. Other experiments (e.g., Rescorla \& Cunningham, 1978) have shown that these sucrose and $\mathrm{NaCl}$ solutions maintain their distinctiveness when compounded. All solutions were prepared with tap water and stored at room temperature for $12 \mathrm{~h}$ prior to their presentation.

Procedure. One week prior to the beginning of the experiment, the rats were placed on a water-deprivation schedule which limited their access to fluids to two 10-min drinking periods, one at 8:00 a.m. and one at 3:00 p.m. They were then separated into six 
groups of six rats each and given preexposure to the compound (Groups CE and CC), the individual elements of that compound (Groups EE and EC), or neither the compound nor its elements (Groups NE and NC). On the single treatment day, rats in Groups $\mathrm{CE}$ and $\mathrm{CC}$ received access to $8 \mathrm{ml}$ of $\mathrm{NaS}$ at 8:00 a.m. and at 11:30 a.m.; rats in Groups EE and EC received access to $8 \mathrm{ml}$ of $\mathrm{Na}$ (or S) at 8:00 a.m. and $8 \mathrm{ml}$ of $\mathrm{S}$ (or $\mathrm{Na}$ ) at 11:30 a.m.; and rats in Groups NE and NC received access to $8 \mathrm{ml}$ of tap water at 8:00 a.m. and at 11:30 a.m. At 3:00 p.m. of the treatment day, all rats received access to $8 \mathrm{ml}$ of NaS. Experimental rats (Groups $\mathrm{CE}, \mathrm{EE}$, and $\mathrm{NE}$ ) were injected intraperitoneally with $.3 \mathrm{M} \mathrm{LiCl}$, $.5 \%$ body weight, immediately after this stimulus presentation, whereas control rats (Groups CC, EC, and NC) received similar injections after a 4-h delay (7:00 p.m.). On each of these three presentations, drinking tubes were removed after 5 min access; all rats consumed the entire volume of liquid on each presentation. No other fluids were given during this treatment day.

The next day served as a recovery day in which all rats were returned to their original water-deprivation schedule. Consumption of $\mathrm{NaS}, \mathrm{S}$, and $\mathrm{Na}$ was assessed over the next 3 days. On the first test day, all rats received $10 \mathrm{~min}$ access to $50 \mathrm{ml}$ of $\mathrm{NaS}$ at 8:00 a.m. and at 3:00 p.m. On the second test day, half of the rats in each group received $10 \mathrm{~min}$ access to $50 \mathrm{ml}$ of $\mathrm{Na}$ at 8:00 a.m. and the other half of the rats received $10 \mathrm{~min}$ access to $50 \mathrm{ml}$ of $\mathrm{S}$; all rats received $10 \mathrm{~min}$ access to tap water at 3:00 p.m. At 8:00 a.m. on the third test day, rats received $10 \mathrm{~min}$ access to $50 \mathrm{ml}$ of the element solution not presented during the previous day.

\section{Results and Discussion}

Table 1 shows median consumption in milliliters of $\mathrm{NaS}, \mathrm{S}$, and $\mathrm{Na}$ during testing. Among the three experimental groups, Group EE consumed significantly (unless otherwise noted, all statistical tests were one-tailed and used the .05 level of significance) more of NaS than Group CE (Mann-Whitney $U=6$ ), which, in turn, consumed significantly more than Group NE $(U=1)$. Thus, element preexposure retarded subsequent conditioning more than compound preexposure. Furthermore, preexposure effects were confined to alterations in conditionability of the flavor CS; the absence of reliable differences in consumption of $\mathrm{NaS}$ among the control groups (Us > 16) indicates that pseudoconditioned aversions or neophobic reactions (if present) were not measurably affected by these preexposure treatments (cf. Domjan, 1976; Domjan \& Bowman, 1974).

Consumption of the individual elements followed similar patterns, as did consumption of the com-

Table 1

Consumption During Testing (in Milliliters) in Experiment 1

\begin{tabular}{crrr}
\hline & \multicolumn{3}{c}{ Solution } \\
\cline { 2 - 4 } Group & $\mathrm{NaS}$ & $\mathrm{Na}$ & $\mathrm{S}$ \\
\hline $\mathrm{EE}$ & 12.0 & 19.5 & 24.5 \\
$\mathrm{CE}$ & 8.0 & 12.0 & 18.0 \\
$\mathrm{NE}$ & 2.0 & 4.0 & 12.0 \\
$\mathrm{EC}$ & 28.5 & 25.5 & 30.0 \\
$\mathrm{CC}$ & 28.0 & 24.0 & 31.0 \\
$\mathrm{NC}$ & 31.0 & 25.0 & 29.5 \\
\hline
\end{tabular}

Note-Each entry for solution NaS represents a mean of the median consumption on the two NaS test trials. Entries for the other two solutions reflect median consumption on individual element test trials. pound. Consumption of $\mathrm{Na}$ was reliably greater in Group EE than in Group CE $(U=7)$, which in turn consumed significantly more than Group $\mathrm{NE}(U=6)$; there were no significant differences in $\mathrm{Na}$ consumption among the control groups ( $U s \geqslant 16$ ). Consumption of $S$ was numerically (but not reliably) greater in Group EE than in Group CE $(\mathrm{U}=8, \mathrm{p}<.10)$; both Group EE and Group CE showed significantly more consumption of $S$ than did Group NE (Us $\leqslant 6.5$ ). In general, within Group EE consumption of the flavor element presented first in preexposure was lower than that of the solution presented second. Although the N (3) for each subgroup was too small to permit statistical evaluation, this apparent difference suggests that the effect of an element preexposure decayed over time (cf. Best \& Gemberling, 1977). There were no reliable differences in consumption of $S$ among the control groups (Us $>16$ ).

The results of Experiment 1 also show that rats treat these flavor-compound stimuli much the same as they treat compounds of exteroceptive stimuli, that is, primarily as concatenations of the individual elements. First, $\mathrm{NaS}-\mathrm{LiCl}$ pairings resulted in the establishment of aversions to $\mathrm{Na}$ and $\mathrm{S}$ individually. Test consumption of $\mathrm{Na}$ was reliably lower in each of the three experimental groups than in each corresponding control groups (Us $\leqslant 6$ ); consumption of $S$ was significantly less in Groups $\mathrm{CE}$ and NE than in Groups $\mathrm{CC}$ and $\mathrm{NC}$, respectively (Us $\leqslant 3.5$ ) and numerically less in Group EE than in Group EC $(U=8, p<.10)$. Second, the observation that conditionability of NaS was reduced more by preexposure to $\mathrm{Na}$ and $\mathrm{S}$ separately than by preexposure to $\mathrm{NaS}$ itself suggests that any configural component unique to the compound was of little importance.

\section{EXPERIMENT 2}

In Experiment 1, the amount of time between flavor preexposure and the conditioning trial was 3.5 and/or $7 \mathrm{~h}$. Best and Gemberling (1977) showed that the effect of a single preexposure was much reduced if that exposure was $23.5 \mathrm{~h}$ or more before conditioning. They proposed (as did Wagner, 1976) that shortterm preexposure effects such as observed in Experiment 1 might be mediated somewhat differently than more permanent effects. Experiment 2 examined whether the preexposure effects found in Experiment 1 could also be observed when longer intervals separated preexposure and conditioning. Experiment 2 also differed from Experiment 1 in that more preexposure trials were administered; this difference was introduced in an attempt to maximize preexposure effects (e.g., Elkins, 1973).

\section{Method}

Subjects and Apparatus. The subjects were 48 male SpragueDawley rats about 150 days old at the beginning of the experiment. 
All had previously served as subjects in appetitive conditioning experiments involving food USs (Noyes pellets), auditory and visual CSs, and food deprivation. The apparatus was the same as that used in Experiment 1, as were the stimuli $\mathrm{NaS}, \mathrm{Na}$, and $\mathrm{S}$. A fourth flavor stimulus, .005 M HC1, was also used in Experiment 2.

Procedure. One week prior to the start of the experiment, the rats were placed on a water-deprivation schedule which limited their access to fluids to two 10-min drinking periods, one at 8:00 a.m. and the other at 4:00 p.m. Fluids were administered to the rats only at these times throughout the experiment. Rats were then randomly separated into six groups of eight rats each and preexposed to the compound (Groups $\mathrm{CE}$ and $\mathrm{CC}$ ), the elements (Groups EE and EC), or neither the compound nor its elements (Groups NE and NC). Half of the subjects in Groups CE and CC received $10-\mathrm{min}$ presentations of unflavored tap water during the first seven drinking periods, and 10-min presentations of the compound during the last seven drinking periods of this phase; the other half received 14 compound presentations. Subjects in Groups $\mathrm{EE}$ and $\mathrm{EC}$ received seven 10 -min presentations of $\mathrm{Na}$ and seven 10 -min presentations of $S$, randomly intermixed, during the 14 drinking periods of the preexposure phase. Groups NE and NC received 14 10-min presentations of unflavored tap water during this phase. No other solutions were presented during the preexposure phase.

All rats then received water (from a standard water bottle rather than the drinking tubes) at 8:00 a.m. and 4:00 p.m. for 2 days. The conditioning phase began on the next (8:00 a.m.) drinking period. Rats in Groups CE, EE, and NE (experimental groups) received $10-\mathrm{min}$ access to $\mathrm{NaS}$ followed immediately by intraperitoneal injection of $.3 \mathrm{M} \mathrm{LiCl}, .5 \%$ body weight, during the 8:00 a.m. drinking periods of each of 2 conditioning days. During the $4: 00$ p.m. drinking periods, rats in these groups received $10 \mathrm{~min}$ access to $\mathrm{H}$, not followed by $\mathrm{LiCl}$. Rats in Groups $\mathrm{CC}$, $\mathrm{EC}$, and $\mathrm{NC}$ (control groups) received $10 \mathrm{~min}$ access to $\mathrm{H}$ followed by $\mathrm{LiCl}$ injection during the two 8:00 a.m. drinking periods, and 10 min access to $\mathrm{NaS}$ not followed by $\mathrm{LiCl}$ injection during the two 4:00 p.m. drinking periods. Thus, in this experiment, $\mathrm{LiCl}$ injections were signaled in both experimental and control groups.

Consumption of $\mathrm{NaS}, \mathrm{S}$, and $\mathrm{Na}$ was tested during the 8:00 a.m. drinking periods of the next three sessions. All rats received 10 min access to $\mathrm{NaS}$ on the first test day, 10 min access to either $\mathrm{Na}$ or $\mathrm{S}$ on the second test day, and $10 \mathrm{~min}$ access to the remaining element on the third test day. Rats received 10 min access to $\mathrm{H}$ during the 4:00 p.m. drinking periods of each test day. $(\mathrm{H}$, rather than water, was presented during these latter drinking periods in an attempt to equate daily fluid consumption of experimental and control rats during testing: all rats received one flavor to which an aversion had been established and one flavor to which an aversion had not been established.)

\section{Results and Discussion}

Figure 1 shows median consumption of $\mathrm{NaS}, \mathrm{S}$, and $\mathrm{Na}$ during the conditioning and test phases of Experiment 2. An aversion to NaS quickly developed in the experimental groups, but not in the control groups. Considering consumption summed over the last $\mathrm{NaS}$ presentation in conditioning and the $\mathrm{NaS}$ test presentation (showing conditioning established after the first and second conditioning trials, respectively), Group NE consumed less NaS than either Group CE $(U=3)$ or Group EE $(U=0)$, while Group EE showed more NaS consumption than Group CE $(U=11.5)$. Within Group CE, there were no reliable differences between the performance of rats receiving seven compound preexposure trials and that of rats receiving 14 such trials; however, the $N$ (4) for each subgroup was too small to justify a conclusion that

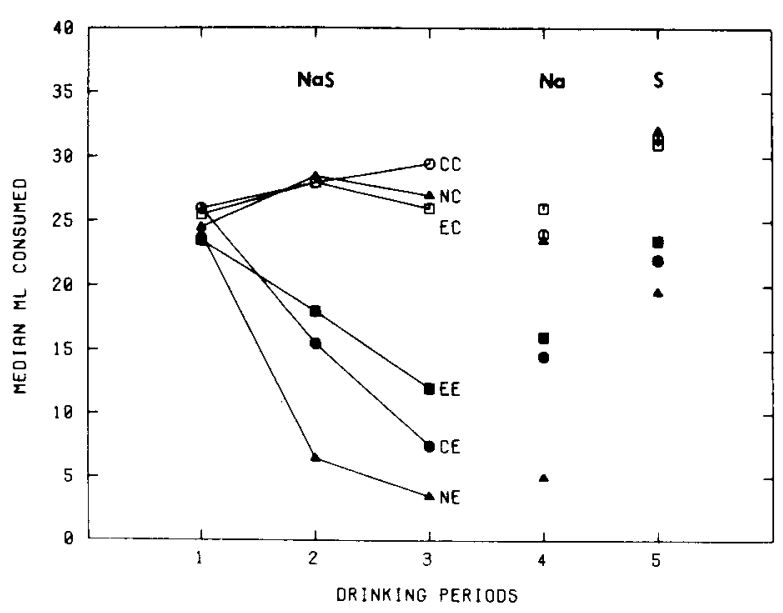

Figure 1. Consumption of $\mathrm{NaS}, \mathrm{Na}$, and $\mathrm{S}$ during conditioning and test phases of Experiment 2. Drinking Periods 1 and 2 show consumption of NaS on the two conditioning trials; Period 3 represents consumption of $\mathrm{NaS}$ in testing. Drinking Periods 4 and 5 show consumption of $\mathrm{Na}$ and $\mathrm{S}$, respectively, during testing. Drinking Period 4 preceded Period 5 for half of the rats in each group; Period 5 preceded Period 4 for the remaining rats. Group designations are indicated to the right of the symbol for Period 3 consumption.

preexposure trials beyond 7 had no additional effect. There were no differences among the control groups (Us $\geqslant 22$ ). Thus, as in Experiment 1, preexposure of constituent elements slowed subsequent conditioning of a compound CS more than did preexposure of that compound itself. Also as in Experiment 1, preexposure did not affect any pseudoconditioned or neophobic aversions which may have been present in the control groups.

Analyses of the data from the individual elements tests showed patterns similar to those obtained for the compound, although few of the differences were reliable. Group NE showed significantly less consumption of Na than either Group CE or Group EE (Us $\leqslant 7$ ); no other differences among the experimental groups were reliable. That aversions were established to each of the individual elements as a result of conditioning the compound is shown by the significant differences in both $\mathrm{Na}$ and $\mathrm{S}$ consumption between each experimental group and its corresponding control group (Us < 10).

\section{GENERAL DISCUSSION}

These experiments showed that preexposure of constituent elements of a compound flavor stimulus reduced the rate of acquisition of a flavor aversion to that compound more than preexposure of the compound itself. The superiority of element preexposure was observed in both short-term (Experiment 1) and long-term (Experiment 2) preexposure procedures. It is also notable that preexposure had no measurable effects on consumption of the various 
flavors in the absence of CS-US pairings. Although such effects may have been obscured by ceiling effects, it is worth noting that we typically find little or no neophobia or pseudoconditioning with these solutions, even with more sensitive testing procedures. Thus, the differential effects of preexposure on the acquisition of conditioning was due to changes in conditionability of those flavors, rather than to modifications of pseudoconditioned or neophobic reactions (cf. Domjan \& Bowman, 1974). These data suggest (as did those of Braveman \& Jarvis, 1978) that preexposure effects on subsequent conditionability and those on neophobic or pseudoconditioned responses might profitably be viewed as being more independent than has sometimes been assumed (e.g., Domjan, 1977).

Many accounts of decremental preexposure effects on conditioning implicate a nonassociative process of habituation. For instance, Domjan (1977) suggested that preexposure habituated the arousal reaction to a novel CS. Since some level of arousal is presumably necessary for conditioning, that arousal habituation would result in lower conditionability of the CS. The results reported here would be consistent with such accounts if it was known that habituation to a stimulus compound was greater after element presentation than after compound presentation. Unfortunately, we know of no data from habituation studies indicating this outcome, nor do most nonassociative accounts of habituation obviously predict such a result.

On the other hand, theories of preexposure effects which assume associative conditioning of some response tendency to the preexposed CS readily account for these data. For instance, Lubow et al. (1976) proposed that decremental preexposure effects involve the "conditioning of inattention" to the CS, reducing its subsequent conditionability. According to their theory, CSs initially evoke an attentional response which is maintained when followed by some other event; if no other event occurs, that response diminishes and inattention is conditioned instead. Any manipulation that affects Pavlovian conditioning, then, if applied during CS preexposure, should affect conditioned inattention similarly. Thus, maximal conditioned inattention (and hence minimal conditionability) to a compound CS should be established by element preexposure, just as Rescorla and Wagner (1972) found that maximal conditioned responding to compound CSs is generated by conditioning of its elements individually. Rescorla and Wagner (1972) argued that the separate reinforcement of stimulus elements permits each element to independently acquire the asymptotic associative strength supportable by the US, whereas the elements must share that same strength when a compound stimulus is reinforced. In the case of stimulus preexposure, separate element presentation might per- mit each element to independently approach an asymptote of conditioned inattention supportable by the nonoccurrence of another event.

The results of Lubow et al. (1976) also suggest another account for our results. They found that inserting a second stimulus in a conditioning relation with (immediately following) the target CS during preexposure considerably reduced the negative effects of preexposure, presumably by maintaining the conditioned attention response to the target $\mathrm{CS}$. In our experiments, presentation of a flavor compound might be viewed as presentation of two flavors in conditioning relations with each other (betweenelement associations within simultaneous compound flavor stimuli are easily established, e.g., Rescorla \& Cunningham, 1978); hence, attention might be maintained more when compounds are presented than when elements are presented alone. In fact, if it is recognized that individual elements might themselves be construed as compound stimuli consisting of several properties, this account might suggest a role for stimulus complexity in determining the outcomes of preexposure experiments: more complex stimuli should show less latent inhibition than simpler stimuli, since conditioning relations among the properties might maintain attentional responses.

\section{REFERENCES}

Best, M. R., \& Gemberling, G. Role of short-term processes in the conditioned stimulus pre-exposure effect and the delay of reinforcement gradient in long-delay taste-aversion learning. Journal of Experimental Psychology: Animal Behavior Processes, 1977, 3, 253-263.

Braveman, N. S., \& Jarvis, P. S. Independence of neophobia and taste aversion learning. Animal Learning \& Behavior, 1978, 6, 406-412.

DomJan, M. Determinants of the enhancement of flavored-water intake by prior exposure. Journal of Experimental Psychology: Animal Behavior Processes, 1976, 2, 17-27.

Domjan, M. Attenuation and enhancement of neophobia for edible substances. In L. M. Barker, M. R. Best, \& M. Domjan, Learning mechanisms in food selection. Waco, Tex: Baylor University Press, 1977.

Domjan, M., \& Bowman, T. G. Learned safety and the CS-US delay gradient in taste-aversion learning. Learning and Motivation, 1974, 5, 409-423.

Elkins, R. L. Attenuation of drug-induced bait shyness to a palatable solution as an increasing function of its availability prior to conditioning. Behavioral Biology, 1973, 9, $221-226$.

Kalat, J. W., \& Rozin, P. "Learned safety" as a mechanism in long-delay taste-aversion learning in rats. Journal of Comparative and Physiological Psychology, 1973, 83, 198-207.

Lubow, R. E. Latent inhibition. Psychological Bulletin, 1973, 79, 398-407.

Lubow, R. E., Schnur, P., \& Rifkin, B. Latent inhibition and conditioned attention theory. Journal of Experimental Psychology: Animal Behavior Processes, 1976, 2, 163-174.

Mackintosh, N. J. Stimulus selection: Learning to ignore stimuli that predict no change in reinforcement. In R. A. Hinde \& 
J. Stevenson-Hinde (Eds.), Constraints on learning. London: Academic Press, 1973.

Malone, P. E., \& Cox, V. C. Development of taste aversion to individual components of a compound gustatory stimulus. Communications in Behavioral Biology, 1971, 6, 341-344.

Rescorla, R. A., \& Cunningham, C. L. Within-compound flavor associations. Journal of Experimental Psychology: Animal Behavior Processes, 1978, 4, 267-275.

Rescorla, R. A., \& Wagner, A. R. A theory of Pavlovian conditioning. Variations in the effectiveness of reinforcement and nonreinforcement. In A. Black \& W. F. Prokasy (Eds.),
Classical conditioning II. New York: Appleton-Century-Crofts, 1972.

WAGNer, A. R. Priming in STM: An information-processing mechanism for self-generated or retrieval-generated depression in performance. In T. J. Tighe \& R. N. Leaton (Eds.), Habitua tion: Perspectives from child development, animal behavior, and neurophysiology. Hillsdale, N.J: Erlbaum, 1976.

(Received for publication August 28, 1979; revision accepted November $19,1979$. 